\title{
Effect of waste polyethylene on properties of methyl salicylate treated natural rubber/low density polyethylene/waste polyethylene composites
}

\author{
W D M Sampath*, I D Perera**, D G Edirisinghe* and \\ V G M J Abhayawardhana* \\ * Rubber Research Institute of Sri Lanka, Telawala Road, Ratmalana, Sri Lanka \\ ** Department of Chemistry, Faculty of Applied Science, University of Jayewardenepura, \\ Sri Lanka
}

\begin{abstract}
Polymer blending has been employed to enable the reuse of recycled industrial and/or municipal plastic waste. Used polythene sheets, which are considered as waste polyethylene (wPE) are a major threat to the environment and hence recycling of these is a way to reduce environmental pollution. The main aim of this study was to develop natural rubber (NR)/low density polyethylene (LDPE) /wPE composites with improved properties using methyl salicylate as the coupling agent. A series of 70:30 NR:LDPE/wPE composites with methyl salicylate were prepared by replacing LDPE with wPE from 0 (control) -25 phpp (parts per hundred parts of polymer) at $5 \mathrm{phpp}$ intervals. Calcium carbonate, $20 \mathrm{phpp}$ and methyl salicylate, $0.5 \mathrm{phpp}$ were also incorporated into every blend composition. The composites were prepared using a laboratory scale internal mixer by melt mixing at a temperature of $150{ }^{\circ} \mathrm{C}$ and a rotor speed of $60 \mathrm{rpm}$. Physico-mechanical properties and fourier transform infrared (FTIR) analyses of the composites were conducted. Water absorption capacity of the composites was also studied. Incorporation of $20 \mathrm{phpp}$ wPE into NR/virgin LDPE composites improved most of the properties. Strength properties and hardness of the composites containing wPE showed an increasing trend with the increase of wPE loading. Water absorption decreased with the increase of wPE loading. Furthermore, it was evident from the results that all the six composites treated with methyl salicylate are highly flexible. Results in overall indicated that the 70:10:20 NR/LDPE/wPE composite is the best in terms of properties.
\end{abstract}

Key words: low density polyethylene, methyl salicylate, natural rubber, polymer composites, waste polyethylene

\section{Introduction}

Mixing of two or more polymers with different chemical compositions or structure and processing conditions is an effective way of combining performance and economic relationships using existing materials. Fundamental problems that affect the properties of blends include weak interfacial behavior and unstable equilibrium phase, 
unwanted physical and chemical interactions between the constituents, incompatible phase morphology, inappropriate blend ratios and complex rheology (Keskkula et al., 1996). However, the blending of wPE with polymer materials is more difficult, and many transitional situations can occur: increasing separation at the intermolecular level formation of cocontinuous morphology, dephasing into dispersed hetero phase morphologies of increasing phase size. Hence, coupling agents are needed to reduce some of such difficulties and to achieve better performance.

Elastomer-thermoplastic is a material that consist of two polymeric materials one having elastomeric behavior at room temperature and the other showing thermoplastic behavior at processing temperature (Montoya et al., 2004). Mostly, they are prepared by melt mixing thermoplastic materials and elastomers under high shearing action. Elastomers such as ethylene-propylene-diene monomer (EPDM), natural rubber (NR) and styrene-butadiene-rubber (SBR) and plastics such as polypropylene (PP), polyethylene (PE), and nylon are usually used as blend components (Petrovic et al., 1996). In this study, NR and LDPE were used to prepare NR/LDPE composites. The soft grades of NR/LDPE blends can replace vulcanized rubber and flexible plastic for applications in footwear, seals, sports items and injection moulded, extruded and thermoforming products.

However, NR/LDPE composite is immiscible and technically incompatible. Interfacial interactions across the phase boundaries could be enhanced by incorporating a suitable compatibilizing agent (Gajanayake et al., 2012). Compatibilization is a method which is used to modify the interfacial properties of the immiscible polymer blends. It causes a reduction of the interfacial surface tension, surface coefficient and stabilization of the desired blend morphology (Utracki, 2003). In literature, LLDPE/GRT (ground rubber tyre) blends have been prepared with ethylene-1-octene copolymer (EOC) compatibilizing agent and physico-mechanical properties were improved (Rocha et al., 2014). Physicomechanical properties of the reactive blends prepared with diallyl maleates suggest its activity as a good compatibilizer for NR/LLDPE blends (Gajanayake et al., 2012).

$\mathrm{NR}$ is an elastomer with excellent properties, which has been exploited in a wide range of applications. LDPE combines high impact strength, toughness, and ductility to make it the material of choice for packaging films, soft grade applications, which is one of its largest applications. Films are used for different applications such as shrink film, thin film for automatic packaging, heavy sacking, and multilayer films where LDPE acts as a seal layer or a water vapor barrier (Baker et al., 2000). Hence, LDPE was selected for this research to make a flexible material by blending with NR.

A large amount of polyethylene waste is generated from plastic product manufacturing industries. Hence, recycling of discarded PE waste (wPE) is a widely adopted method of reducing 
W D M Sampath et al.

municipal solid waste by preparing blends for constructive applications using lower levels (Rector, 2006). Work carried out by Rector, 2006, has revealed that wPE is one of the solid waste types that could be blended with NR and pure LDPE to prepare thermoplastic elastomers (TPEs). As it can be seen in the literature, composite prepared with recycled high density polyethylene (rHDPE)/NR/(Kenaf powder) KP reduced the tensile strength, elongation at break, but increased the stabilization torque and the tensile modulus. SEM images of fracture surface showed that fibrillation due to addition of rHDPE (Cao et al., 2012).

Filler is another major component widely added to the TPE blends to achieve cost benefits and certain property improvements in real industrial applications. $\mathrm{CaCO}_{3}$ is one of such important inorganic powders and widely used as a filler in plastic and rubber industry. Dispersion of inorganics in polymers, and adhesion of a polymer to inorganic filler are difficult since many thermoplastics and rubbers, such as olefin-based polymers, are non-polar. However, it is known that $\mathrm{CaCO}_{3}$ is the most widely used non-reinforcing filler in natural rubber composites as an inexpensive filler and could be used at high loadings.

The overall performance of the TPEs is enhanced upon dynamic vulcanization (DV). DV is used to make 'semi-rigid' rubber-plastic compositions. Also, DV process makes the morphology of the system more stable. Hence, in this study, each composite was prepared by DV method. In this work, performance of
NR/LDPE/wPE blends, compatibilized using a novel coupling agent namely methyl salicylate through $\mathrm{CaCO}_{3}$.was studied. Methyl salicylate would perform as an intermediate between $\mathrm{CaCO}_{3}$ and nonpolar NR, LDPE and wPE phases. Methyl salicylate chemically interacts with $\mathrm{CaCO}_{3}$ and the resultant complex interacts with $\mathrm{NR}$, LDPE and wPE phases. These interactions via methyl salicylate are expected to enhance the compatibility of $\mathrm{CaCO}_{3}$ with NR/LDPE/wPE composite.

\section{Materials and Methods}

Natural rubber (RSS-2) was supplied by the Rubber Research Institute of Sri Lanka. LDPE was supplied by Deluxe Plastics Ltd., Sri Lanka. $\mathrm{CaCO}_{3}$ (filler) having a mean particle size of $2 \mu$ was obtained from Lanka Minerals \& Chemicals (Pvt.) Ltd., Sri Lanka. Other compounding ingredients; sulphur and dicumyl peroxide (DCP) (vulcanizing gents), stearic acid and zinc oxide $(\mathrm{ZnO})$ (activator system), N-tert-butyl-2benzothiazole sulfenamide (TBBS) (accelerator), IPPD (N-isopropyl N'phenyl p-phenylene diamine) (antioxidant) and methyl salicylate were purchased from the local market and used as received. wPE was obtained from Elastomeric Engineering (Pvt.) Ltd., Sri Lanka.

\section{Preparation of NR/LDPE composites}

A series of NR/LDPE/wPE composites was formulated by varying wPE loading from 0 to 25 phpp. The formulation of the composites is given in Table 1 . The composite without wPE was considered as the control. The composites were 
prepared by melt mixing using a Brabender Plasticorder operated at a temperature of $130{ }^{\circ} \mathrm{C}$, and at a rotor speed of $70 \mathrm{rpm}$. Total mixing time was kept constant at 14 minutes. Mixing cycle used in the preparation of the composites is given in Table 2 .

Table 1. Formulations of the NR/LDPE/wPE composites

\begin{tabular}{|c|c|}
\hline Ingredient & $\begin{array}{l}\text { Parts per hundred parts } \\
\text { of polymer (pphp) }\end{array}$ \\
\hline NR & 70 \\
\hline LDPE & $\begin{array}{llllll}30 & 25 & 20 & 15 & 10 & 5\end{array}$ \\
\hline $\begin{array}{l}\text { wPE } \\
\mathrm{CaCO}_{3}\end{array}$ & $\begin{array}{llllll}0 & 5 & 10 & 15 & 20 & 25\end{array}$ \\
\hline $\mathrm{DCP}$ & 0.5 \\
\hline Sulphur & 0.5 \\
\hline Zinc oxide & 3.5 \\
\hline Stearic acid & 2.0 \\
\hline TBBS & 0.5 \\
\hline IPPD & 0.7 \\
\hline Coupling agent & 0.5 \\
\hline
\end{tabular}

Table 2. Mixing cycle of the NR/LDPE/wPE composites

\begin{tabular}{ll}
\hline $\begin{array}{l}\text { Total time } \\
\text { (min) }\end{array}$ & Ingredient \\
\hline 0 & $\mathrm{LDPE}$ \\
4 & $\mathrm{NR}$ \\
6 & $\mathrm{ZnO}+$ Stearic acid +IPPD \\
7 & $1 / 2 \mathrm{CaCO}_{3}+1 / 2 \mathrm{CA}$ \\
9 & $1 \frac{1}{2} \mathrm{CaCO}_{3}+1 / 2 \mathrm{CA}$ \\
11 & $\mathrm{TBBS}$ \\
12 & Sulphur $+\mathrm{DCP}$ \\
14 & Dumping the compound \\
\hline
\end{tabular}

NR/LDPE/wPE composites were compressed in an electrically heated hydraulic press at $150{ }^{\circ} \mathrm{C}$ under $3.5 \mathrm{bar}$ pressure for 15 minutes to produce $2 \mathrm{~mm}$ thick sheets. The processing conditions and compression moulding conditions were selected within the standard parameter ranges used in preparation of NR/LDPE/wPE composites. Test specimens were stamped from the moulded sheets according to the ISO standard.

\section{Physico-mechanical properties}

Tensile properties and tear strength of NR/LDPE composites were determined using Instron tensile testing machine according to BS ISO $37: 2010$ and BS ISO 34-1:2010, respectively. Dumbbell shaped tensile test specimens and angle shaped tear test specimens were used. Strain rate was maintained at 50 $\mathrm{mm} / \mathrm{min}$, and the extension was measured as the separation of the crosshead. Hardness of the composites was determined using dead load hardness tester according to BS ISO 48:2010.

\section{FTIR spectroscopy}

FTIR spectra of the oven dried gels were obtained using attenuated total reflectance (ATR) technique, using a Nicolet 380 FTIR spectrometer. Spectra were recorded in the range of 400 to $3500 \mathrm{~cm}^{-1}$ operated at a resolution of 4 $\mathrm{cm}^{-1}$.

\section{Water absorption}

Water absorption was obtained by immersion of test specimens having dimensions $30 \mathrm{~mm} \times 10 \mathrm{~mm} \times 2 \mathrm{~mm}$ in water at room temperature for 72 hours. Increase in weight to the initial weight of the specimen, as a percentage was reported as the water absorption. 
W D M Sampath et al.

\section{Results and Discussion \\ Physico-mechanical properties of NR/LDPE/wPE composites}

Hardness of NR/LDPE/wPE composites at different wPE loadings is shown in Figure 1. Hardness of all composites was in the range of 40 to 60 IRHD. According to the Figure 1, composite prepared with wPE loading 20 phpp shows the highest hardness value and it is even higher than that of the control (without wPE). Highest stress value is also shown by the former composite (Fig. 2), which means that it has the highest crystallinity compared to other composites. Further, composites prepared with wPE loading of 10 phpp showed the lowest hardness value compared to other wPE composites and control. Other than that, the hardness of composites fluctuates and shows a cyclic pattern with wPE loading. Sulphur and DCP were used as the main vulcanizing agents in this study. DCP initiates radical formation on the LDPE backbone by hydrogen abstraction and chain scission (Maziad et al., 2009) and it makes strong $\mathrm{C}-\mathrm{C}$ crosslinks with NR, LDPE and wPE phases. Therefore, it could be a reason for the enhancement of crosslink density of composites. In contrast, literature suggests that peroxides could act as chemical devulcanizing agents for sulphur vulcanized rubbers (Joseph et al., 2016). This would be a possible reason for the decrease in hardness at 10 phpp wPE loading.

Figure 2 shows crystalline behavior of composites at 0 phpp and 5 phpp wPE loadings and semi-crystalline behavior for the other composites. When more wPE containing long branches are present in the composite, short branches

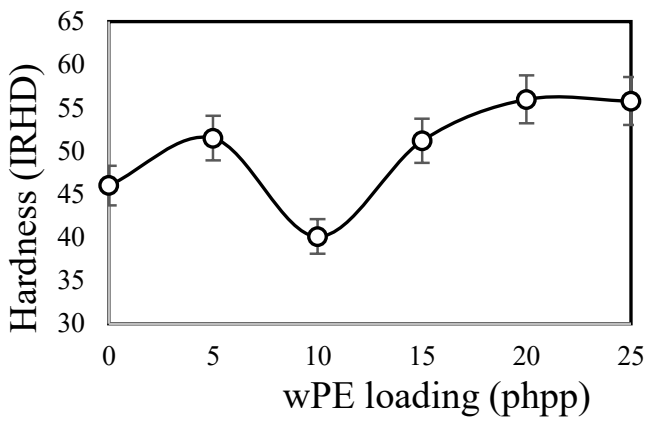

Fig. 1. Variation of hardness of NR/LDPE/ wPE composites with wPE loading

may generate during reprocessing resulting in increasing crystallinity. According to the Figure 2, the composite prepared with wPE loading of $20 \mathrm{phpp}$ shows the highest elongation and it is even higher than that prepared without wPE. In addition, highest stress value is shown by the former composite, which means that it has the highest crystallinity compared to other composites.

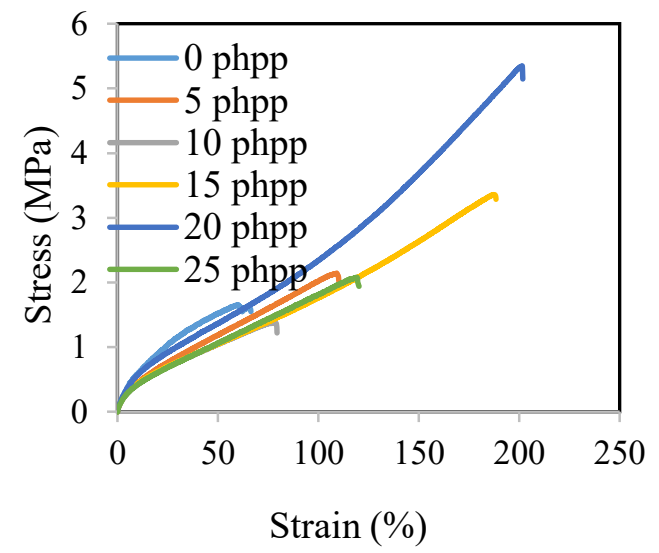

Fig. 2. Strain-stress curves of NR/LDPE/ wPE composites

Figure 3 shows a marked increase in tensile strength from wPE loading of 10 
to $20 \mathrm{phpp}$. This could be attributed to a phase change. The tensile strength of wPE loading at 20phpp is higher than that of the control. The reason for the higher tensile strength of wPE loading at 20phpp could be attributed to good inter molecular interaction between the two polymer phases and lower surface tension at the interface (Rector, 2006). This in turn would result in making a good intermediate between NR and LDPE. Further, the tensile strength of the composites depends mostly on the adhesion between the two phases (Borovanska et al., 2012) and it may be concluded that the adhesion between the components in the 70 phpp NR and 10/20 LDPE/wPE is better than that in the other composites at $20 \mathrm{wPE}$ ratio. According to statistical analysis (one way ANOVA) at $95 \%$ confidence interval, there is an effect of wPE loading on properties of 70/30 NR/LDPE:wPE composites $(\mathrm{p}<0.001)$.

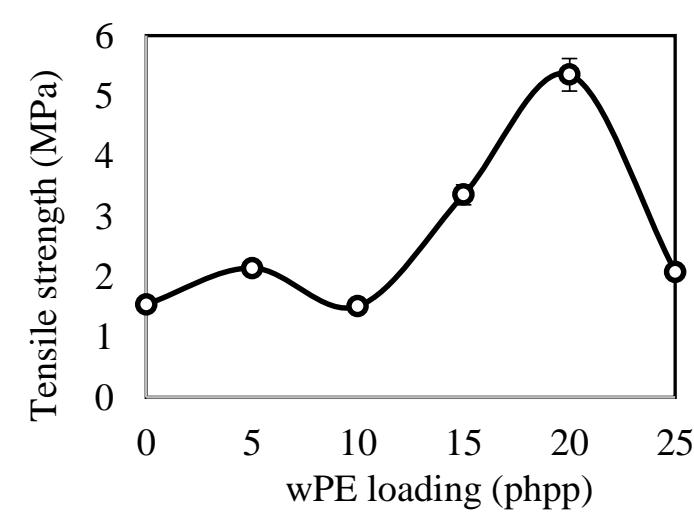

Fig. 3. Variation of tensile strength of NR/LDPE/wPE composites with wPE loading
Elongation designates elasticity and amorphous behaviour of a polymer material. Figure 4 shows a sin pattern of elongation at break from control to wPE loading of $25 \mathrm{phpp}$. There is a significant variation in difference between wPE loading of $10 \mathrm{phpp}$ and $15 \mathrm{phpp}$, however the variation from wPE loading of 15 phpp to 20 phpp is not so significant. The wPE loading of $20 \mathrm{phpp}$ shows the highest elastic properties compared to the other composites. This could be due to good dispersion of the filler $\mathrm{CaCO}_{3}$ through methyl salicylate. The control exhibits the lowest elongation at break. According to the stress-strain curves (Fig. 2), the pattern of control shows crystalline behavior. On the other hand, crystalline materials generally show low elongation properties (Monticelli et al., 2012) and this could be another reason for lower elongating ability of the crystalline composite.

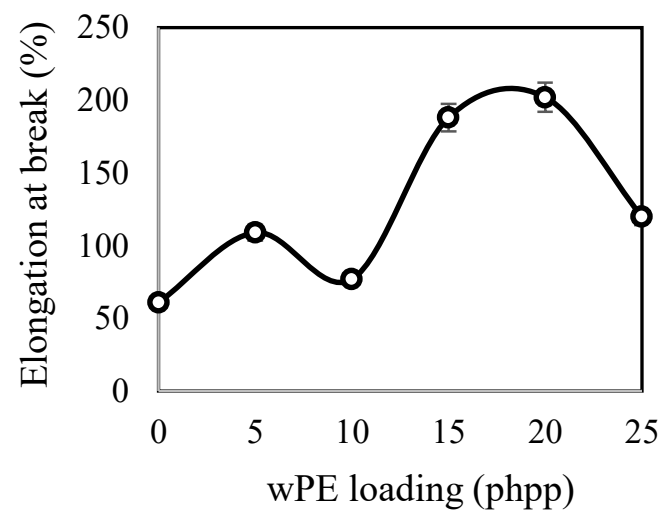

Fig. 4. Variation of elongation at break of NR/LDPE/wPE composites with wPE loading 
W D M Sampath et al.

Modulus can be taken into account when explaining crystallinity, amount of orientation and material strength. Modulus at 5\% elongation shows a decreasing pattern from wPE loading of 0 phpp to 10 phpp. Hence, low amount of wPE could act as a filler and it will not be uniformly distributed throughout the composite resulting in a lower modulus at 5 phpp and 10 phpp compared to that of the control. The composite prepared with wPE loading of 20 phpp shows the highest modulus. This is probably due to formation of a stronger intermediate between NR and LDPE with the increase of excess curatives generating from wPE (Atuanyaa et al., 2004). On the other hand, presence of a higher amount of curatives increases crosslink density and hence crystallinity. Therefore, wPE loading of 20 phpp indicates the highest crosslink density and hence highest crystallinity, which in turn gives the highest modulus. Further, modulus at 5\% elongation of composites shows a cyclic pattern in the variation of wPE loading. Moreover, wPE is a cured material and it could have unreacted chemicals or ingredients of different loadings such as crosslinking agent, processing aid, etc. (Burillo et al., 2002). Furthermore, unreacted crosslinking agent would have remained in the wPE and it would have reacted with the virgin NR and LDPE at the processing temperature. Therefore, this could be a possible reason for the fluctuation observed in Figure 5.

Tear strength of a polymeric material depends mainly on the crack propagation property. Crack propagation of the composites decreases with the increase of wPE loadings up to $10 \mathrm{phpp}$. Tear strength results (Fig. 6) also confirm the

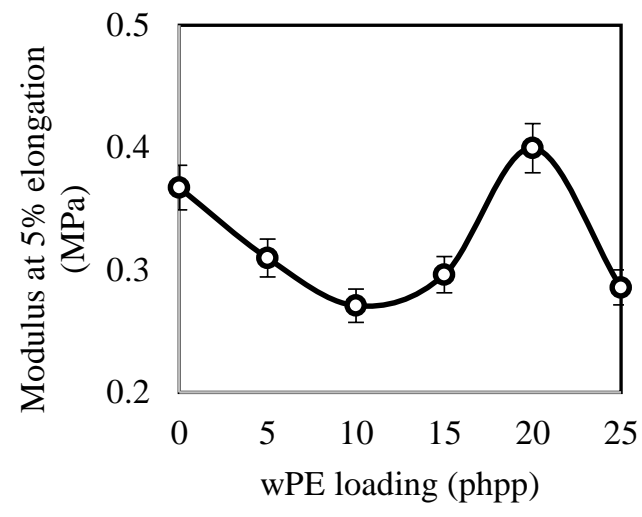

Fig. 5. Variation of modulus at 5\% elongation of NR/LDPE/wPE composites with wPE loading

formation of a good intermediate between the two polymer phases when the amount of wPE is increased. Further, tear property has been significantly increased when the wPE loading is increased from $10 \mathrm{phpp}$ to $25 \mathrm{phpp}$. According to literature, waste plastics are compatible with thermoplastics and thus are frequently used for impact modification and improvement in stresscrack resistance (Borovanska et al., 2012).

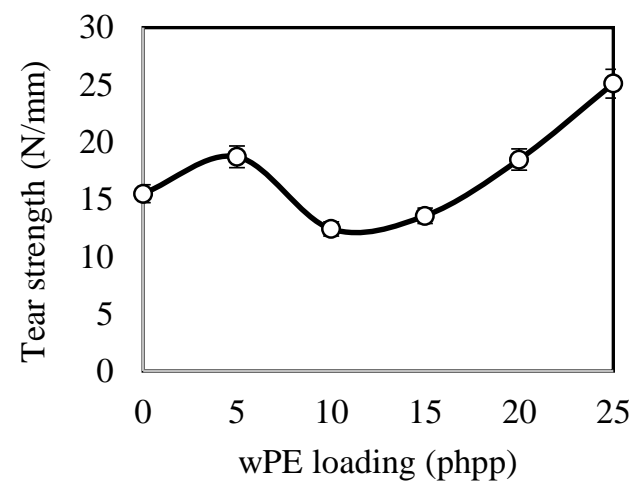

Fig. 6. Variation of tear strength of NR/LDPE/wPE composites with wPE loading 


\section{Fourier Transform Infrared (FTIR) Spectroscopic Analysis}

Figure 7 presents the FTIR spectra of the composites at different wPE loadings. The composite prepared with wPE loading of 20 phpp exhibits a peak assignment at $1378 \mathrm{~cm}^{-1}$ (Fig. 7b). This could be assigned to $-\mathrm{C}-\mathrm{O}-\mathrm{H}$ in-plane bending vibrations (Brook, 2000). Thus, the formation of above bonds proves that the composite at wPE loading of $20 \mathrm{phpp}$ achieved a better interaction between NR, LDPE, and other ingredients. This would also support increased tensile and tear properties at $20 \mathrm{phpp}$ wPE loading.
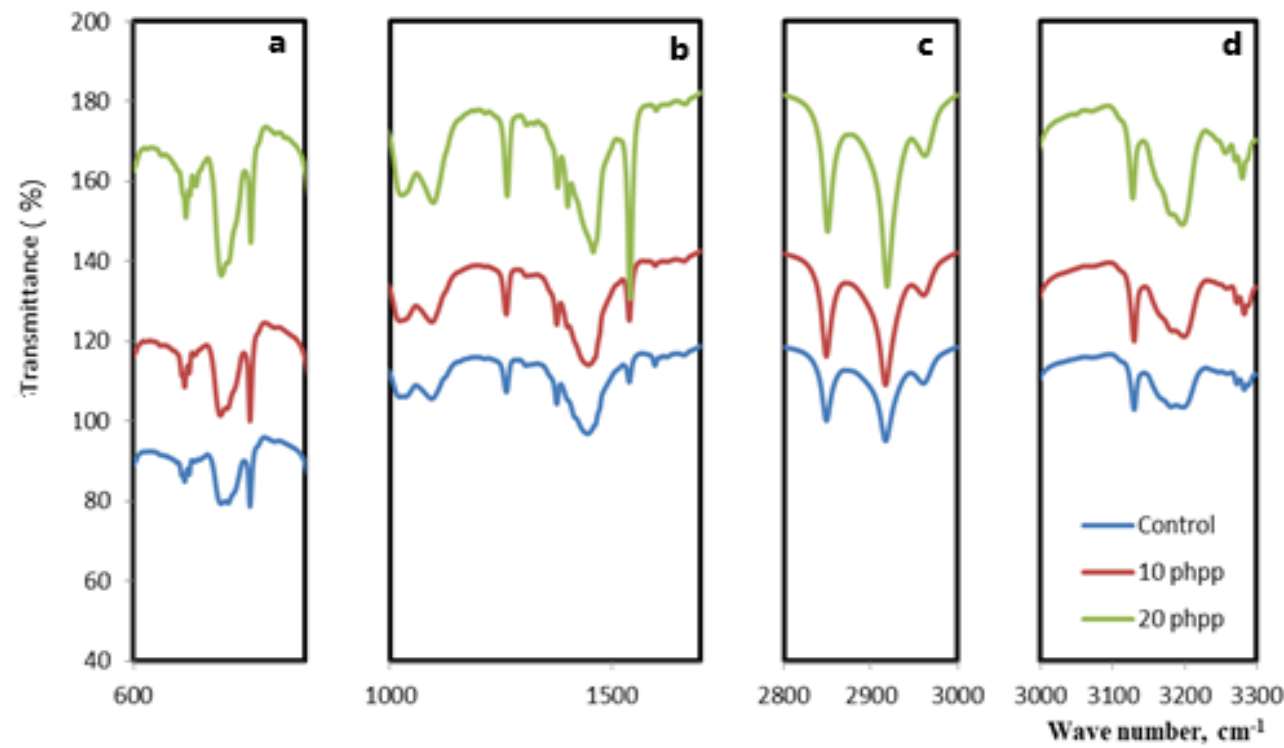

Fig. 7. FTIR spectra of gels of the control and composites with wPE for different regions

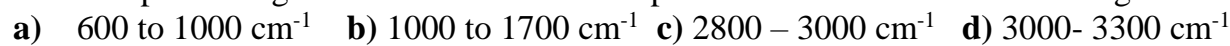

Water absorption of NR/LDPE/wPE composites

As per Figure 8, water absorption of all the composites is less than $0.35 \%$. Water absorption decreases with the addition of wPE loading of $5 \mathrm{phpp}$, and further declines from wPE loading of $10 \mathrm{phpp}$ to 20 phpp. NR and LDPE are organic polymers, and hence they do not react with inorganic water molecules. The composite prepared with wPE loading at $10 \mathrm{phpp}$ indicated the highest water absorption and, it could be due to the presence of unreacted organic methyl salicylate. The lowest water absorption at wPE loading of 20 phpp confirms a good adhesion between NR and LDPE phases of the composites at that wPE loading. Further, wPE-aggregate at all replacement levels is due to the higher porosity of these composites, as higher water absorption generally indicates higher porosity (Saikia et al., 2013). In addition, 20 phpp loading of $\mathrm{CaCO}_{3}$ has 
W D M Sampath et al.

affected to make a strong adhesion with 20 phpp loading of wPE via methyl salicylate. As a result, the free volume is decreased in the 70/10/20 NR/ $\mathrm{LDPE} / w P E$ composite due to increase in the dispersibility of $\mathrm{CaCO}_{3}$.

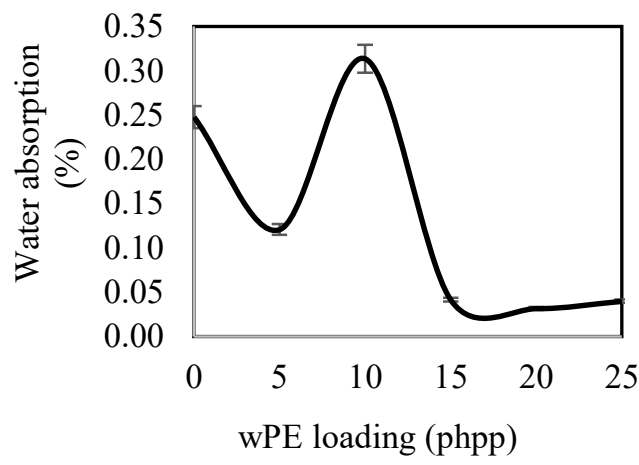

Fig. 8. Variation of water absorption of NR/LDPE/wPE composites with wPE loading

\section{Conclusion}

The composite prepared with 20 phpp loading of wPE showed remarkable physico-mechanical properties in terms of hardness, tensile strength, tear strength, and elongation at break. Therefore, 20 phpp is identified as the optimum loading for 70/30 NR/LDPE composites. In addition, the properties of composites fluctuated with the addition of different loadings of wPE due to different amounts of cured and unreacted substances present in wPE. Further, water absorption decreased with the addition of wPE. The composite with wPE loading of 20 phpp showed the lowest water absorption capacity. Hence, this composite would be suitable to produce water resistant products such as roofing sheets and flow tiles.

\section{References}

Atuanyaa, C U, Edokpiab, R O and Aigbodionc, V S (2004). The physicomechanical properties of recycled low density polyethylene (RLDPE)/bean pod ash particulate composites. Journal of Polymer Technology 17 (4), 23-34.

Baker, A M M and Mead, J (2000). Thermoplastics. In: Modern Plastics Handbook, McGraw-Hill, Inc.

Borovanska, I, Dobreva, T, Benavente, R, Djoumaliisky, S and Kotzev, G (2012). Quality assessment of recycled and modified LDPE/PP blends. Journal of Elastomers \& Plastics 44 (6), pp.479497.

Bosshard, A W and Schlumpf, H P (1987). Fillers and reinforcements in plastics additives 2/e. (Eds. R Gachter and $\mathrm{H}$ Muller), Hanser Publishers, New York, pp.407-420.

Brook, M A and Organic, O (2000). Polymer Chemistry. Wiley, New York.

Cao, X V, Ismail, H, Rashid, A A and Takeichi, T (2012). Kenaf powder filled recycled high density polyethylene/natural rubber biocomposites: The effect of filler content. International Journal of Integrated Engineering. Vol. 4 No 1.

Gajanayake, G K R P (2014). Effect of composition on physicochemical properties of linear low density polyethylene/natural rubber blends. Doctoral Dissertation, University of Sri Jayewardenepura, Nugegoda.

Joseph, A M, George, B, Madhusoodanan, K $\mathrm{N}$ and Alex, R (2016). The current status of sulphur vulcanization and devulcanisation chemistry: Devulcanisation. Rubber Science, 29 (1), 62-100.

Keskkula, H and Paul, D R (1996). "Polymer Composites" in Kirk Othmer, Encyclopedia of Chemical Technology, John Willey \& Sons Inc. 
Maziad, N A, El-Nashar, D E, \& Sadek, E M (2009). The effects of a silane coupling agent on properties of rice husk-filled maleic acid anhydride compatibilized natural rubber/low-density polyethylene blend. Journal of Material Science 44 (10), 2665-2673, https://doi.org/ 10.1007/s10853-009-3349-3.

Monticelli, O, Bocchini, S and Frache, A (2012). Simple method for the preparation of composites based on PA6 and partially exfoliated graphite. Journal of Nanomaterials 8 (5), 42-47.

Montoya, M, Tomba, J P, Carella, J M and Gobernado-Mitre M I (2004). European Polymer Journal 40, p.2757.

Petrović, Z S, Budinski-Simendić, J, Divjaković, V and Škrbić, Ž (1996). Effect of addition of polyethylene on properties of polypropylene/ethylenepropylene rubber composites. Journal of Applied Polymer Science 59 (2), pp.301310.

Rector, Y P (2006). Polymers Characteristics. Applications and Processing. $2^{\text {nd }}$
Edition. http://www. virginia.edu/bohr/ mse209/chapter16.htm University of Virginia. Chapter 16

Saikia, N and Brito, J D (2013). Waste polyethylene terephthalate as an aggregate in concrete. Materials Research 16 (2), pp.341-350.

Sampath, W D M, Egodage, S M and Edirisinghe, D G (2019). Effect of Peroxide Loading on Properties of Natural Rubber and Low-density Polyethylene Composites. Journal of Physical Science 30 (3).

Utracki, L A and Favis, B D (1989). Polymer Alloys and Composites. Vol. 4, pp. 121185. Marcel Dekker: New York.

Address for correspondence: $\mathrm{Mr} \mathrm{W} \mathrm{D}$ M Sampath, Research Officer, Rubber Technology \& Development Dept., Rubber Research Institute of Sri Lanka, Telewala Road, Ratmalana, Sri Lanka.

e-mail:wikcramage@yahoo.com 